\title{
¿Dónde están y quiénes son los que protestan contra la globalización? Caracterización de las organizaciones participantes en el Foro Social Mundial 2001, 2004 y 2008*
}

\author{
Where and who are those who Protest against \\ Globalization? Characterization of the \\ Participant Organizations at the World Social \\ Forum 2001,2004 and 2008
}

Carolina Cepeda Másmela**

Recibido: 16 de septiembre de 2016

Aprobado: 28 de octubre de 2016

Disponible en línea: 20 de diciembre de 2016

\section{Resumen}

Este artículo ofrece una caracterización de las organizaciones y los movimientos sociales que suscribieron las declaraciones oficiales del Foro Social Mundial (FMS) en sus versiones de 2001, 2004 y 2008, con el fin de discutir algunas de las críticas más recurrentes que hay frente a este. Para ello, enmarca el análisis dentro de la literatura sobre movimientos sociales globales desde una perspectiva crítica en relaciones internacionales, cuestionando también el carácter unidimensional que las perspectivas liberales le asignan a la sociedad civil. Se ilustran los principales rasgos de los participantes respecto del origen, la frecuencia de la participación, las reivindicaciones centrales y los tipos de

\begin{abstract}
This article offers a characterization of the organizations and social movements subscribing the official declarations of the World Social Forum in its versions of 2001, 2004 and 2008. Its aim is to discuss some of the most recurrent criticisms that exist against them by means of: framing the analysis within the literature on global social movements from a critical perspective in IR from which the unidimensional character that liberal perspectives assign to civil society is also questioned; and describing the participants in terms of origin, frequency of participation, central claims and types of organization. The article concludes with several reflections on the need to investigate in greater depth the role
\end{abstract}

** Pontificia Universidad Javeriana (Bogotá, Colombia). Correo electrónico: ycepeda@javeriana.edu.co 
organización. El artículo concluye con varias reflexiones sobre la necesidad de indagar con mayor profundidad sobre el rol de organizaciones y movimientos concretos, la construcción de coaliciones en el FMS y las discusiones alrededor de temáticas centrales por ser trabajadas allí.

\section{Palabras clave}

Foro Social Mundial; sociedad civil; coaliciones transnacionales; globalización neoliberal alternativas

\section{Cómo citar este artículo:}

Cepeda-Másmela, C. (2016). ¿Dónde están y quiénes son los que protestan contra la globalización? Caracterización de las organizaciones participantes en el Foro Social Mundial 2001, 2004 y 2008. Papel Político, 21(2), 505-536. https://doi.org/10.11144/ Javeriana.papo21-2.dqog of specific organizations and movements, the construction of coalitions within the Forum and the discussions around the central issues to be discussed there.

\section{Keywords}

World Social Forum; civil society; transnational coalitions; neoliberal globalization; alternatives 


\section{Introducción}

El proceso de construcción y consolidación de redes y movimientos sociales transnacionales, cuyas primeras manifestaciones pueden encontrarse en las campañas en pro de la abolición de la esclavitud (Keck y Sikkink, 2000), se ha intensificado desde la década de 1980. Uno de los casos más importantes en ese sentido es el del Foro Social Mundial (FSM), entendido como una de las expresiones del movimiento alterglobalización (Cepeda, 2015), donde convergen distintos movimientos, organizaciones y activistas sociales que se oponen al proceso de globalización neoliberal y buscan construir una alternativa.

El FSM se ha analizado con exceso de optimismo debido a que articula distintas formas de oposición al neoliberalismo y fortalece la discusión en términos globales; sin embargo, han surgido críticas internas y externas, según las cuales se acusa a ciertos movimientos y organizaciones de intentar dominar la coalición e imponer sus intereses particulares. De igual forma, existe una discusión sobre el rol que este debería tener: limitarse a ser espacio de discusión o ser un actor comprometido con la toma de decisiones y la implementación de estrategias.

Estas críticas, independiente de qué tan fundamentadas están, permiten superar la idea liberal de que actores de la denominada sociedad civil global como el FSM son homogéneos y unificados (Kaldor, 2005); al contrario, pone de manifiesto la existencia de tensiones y relaciones de poder en su interior. Sin embargo, es preciso hacer un análisis descriptivo de tales críticas, con el fin de fundamentarlas o cuestionarlas, teniendo en cuenta que el argumento central sugiere que los actores de la sociedad civil son heterogéneos y pueden presentar tensiones internas, más allá de lo deseable de las causas y los valores que defienden.

En ese sentido, un primer paso en el estudio del FSM es describirlo respecto de quiénes hacen parte de él y qué tipo de intereses y visiones de mundo tienen. Se han realizado algunos trabajos que buscan indagar sobre esto en términos individuales: trazar perfiles sociológicos de los participantes, definiéndolos a partir de edad, género, tendencia ideológica, trayectoria de movilización social, lugar de procedencia y membrecía a un movimiento u organización social (Della Porta, 2005; FSM, 2005; Steger, Goodman y Wilson, 2013).

Estos trabajos son muy valiosos, pero no dan cuenta de la participación colectiva, un tipo de participación de crucial importancia si se tiene en cuenta que el FSM se ha entendido como una gran coalición de movimientos y organizaciones sociales, y el conflicto y la heterogeneidad se han manifestado en este nivel. Así, es necesario saber quiénes participan en el FSM, esto es, qué organizaciones, desde qué regiones del mundo y con qué tipo de reivindicaciones.

Este artículo identifica los principales actores, las reivindicaciones centrales y la continuidad del FSM. Para ello, se toman tres versiones de este: primera versión en 2001, primera versión fuera de Brasil en 2004 y la versión de 2008 cuando se realiza 
una semana de la movilización y acción global, en lugar de un evento centralizado y localizado geográficamente. ${ }^{1}$ Todo con el fin de identificar algunas diferencias iniciales que permitan darle sustento o desmitificar las críticas más frecuentes que se han hecho sobre el predominio de cierto tipo de organizaciones y regiones del mundo. ${ }^{2}$

Para tales fines, este trabajo se divide en cinco secciones. Primero, una serie de precisiones conceptuales, donde se explora la literatura sobre actores sociales transnacionales; segundo, una contextualización metodológica sobre la forma cómo se realizó esta investigación; tercero, los antecedentes del FSM y las principales críticas que hay sobre el proceso mismo, tomando como base la literatura específica sobre este tema; cuarto, una caracterización de las organizaciones participantes en relación con las críticas señaladas; y quinto, algunas reflexiones con miras a investigaciones complementarias.

\section{Precisiones conceptuales}

Es posible afirmar que la estructura de oportunidad política para la movilización social transnacional o interconectada se ha modificado. Los cambios tecnológicos han producido cambios alrededor del acceso a la información y las posibilidades de viajes e intercambios físicos (Laïdi, 1997). Con ello, hay, por un lado, una mayor visibilidad de aspectos que antes se consideraban aislados o específicos; y por el otro, una modificación de las capacidades de distintos actores sociales para aproximarse a tales aspectos que incrementa sustancialmente el número de problemas visibles y por ser resueltos por la misma sociedad (Florini, 2001).

Siguiendo esa misma línea, Tarrow (2007) propone una definición de internacionalismo para ayudar a clarificar el concepto de estructura de oportunidad política internacional: " "Una estructura densa y triangular entre Estados, actores no estatales e instituciones internacionales, y las oportunidades que ello produce para que los actores se comprometan en acciones colectivas en diferentes niveles de este sistema” (p. 75).

En ese marco de oportunidad política, aparecen actores transnacionales no estatales organizados de diferentes formas. Khagram, Riker y Sikkink (2002, pp. 7-8) argumentan que se pueden clasificar como:

1. Organizaciones no gubernamentales transnacionales, grupos privados y voluntarios, más profesionalizados que un movimiento social, con una estructura de

\footnotetext{
${ }^{1}$ La relevancia de estas fechas se comprenderá con mayor precisión a lo largo del trabajo, cuando se presenten las críticas realizadas al FSM por su centralidad en Brasil y el predominio de movimientos, como el Movimento dos Trabalhadores Rurais Sem Terra (MST) en su organización y dirección.

${ }^{2}$ La autora agradece a Laura Natalia Cepeda, estudiante de Ciencia Política de la Pontificia Universidad Javeriana, quien ayudó a codificar la información para construir la base de datos de este trabajo.

${ }^{3}$ Sidney Tarrow define el concepto de oportunidad política dentro del estudio de los movimientos sociales nacionales como "dimensiones congruentes - aunque no necesariamente formales o permanentes - del entorno político que ofrece incentivos para que la gente participe en acciones colectivas al afectar a sus expectativas de éxito o fracaso" (1997, p. 155).
} 
toma de decisión, miembros de al menos tres países y unos objetivos que apuntan a blancos internacionales.

2. Redes de defensa transnacional, grupos de actores de diferentes países que comparten ciertos valores y discursos, manejan densos intercambios de información y servicios, y carecen de coordinación en sus tácticas de movilización.

3. Coaliciones transnacionales, que tienen una estructura similar a la de las redes, salvo porque sí tienen una coordinación de estrategias compartidas para influir en el cambio social.

4. Movimientos sociales transnacionales que comparten propósitos y solidaridad en más de un Estado, son capaces de generar movilizaciones coordinadas y sostenidas en más de un país y tienen en la protesta y la acción disruptiva sus formas principales de acción.

Para este trabajo, resultan útiles las categorías de movimientos sociales transnacionales y coaliciones transnacionales, en cuanto mucho de la discusión sobre el FSM ha girado en torno a su carácter: ¿̇espacio deliberativo? (Glasius, 2005), ¿̇movimiento global?, ¿̇coalición transnacional? (Teivainen, 2005), y las aspiraciones que puede tener de incidir en la política internacional y en las distintas políticas domésticas nacionales a partir de ello. De ahí la necesidad de ahondar en estos dos conceptos.

Della Porta (2003) define los movimientos sociales globales como "actores organizados en torno a retículos iguales a los del Estado nacional, dotados de identidad global, que defienden sus causas como supranacionales, organizando campañas de protestas que impliquen más Estados”. A partir de ello, se pueden identificar tres elementos fundamentales para los movimientos globales: 1) identidad global, entendida como una interpretación común de la realidad; 2) repertorios de acción no convencionales como protestas en el ámbito transnacional contra actores internacionales; y 3) redes organizacionales, esto es, construcción de redes en diferentes países, a las que los individuos se vinculen de manera personal, teniendo siempre la oportunidad de pertenecer o no (Della Porta, Andretta, Mosca y Reiter, 2006, pp. 29-31).

Tarrow, por su parte, afirma que las coaliciones transnacionales varían de acuerdo con dos dimensiones: "a. la duración de la conexión entre actores y b. su grado de institucionalización” (2005, p. 15). A partir de esas dos dimensiones, existen tres tipos de coalición, que se diferencian, además, por su capacidad de cohesión, solidaridad y sostenimiento de la acción colectiva:

1. Coaliciones eventuales, formadas para manifestaciones internacionales que no avanzan más allá de esa coyuntura, como las megaprotestas globales. 
2. Coaliciones de campaña, que se forman y reforman alrededor de temas específicos y logran sostenerse en un tiempo limitado, como en el caso de las campañas contra el Área de Libre Comercio de las Américas en América Latina.

3. Coaliciones durables que son aquellas que persiguen un programa en curso y están pensadas a largo plazo, como podría ser el caso del FSM.

Como ya se señaló, estos actores tienden a analizarse como homogéneos y con intereses deseables por y para toda la humanidad. Así, por ejemplo, dado que el carácter de asociación a las redes y los movimientos sociales globales es voluntario y estos materializan la participación política "desde abajo", se tienden a juzgar como algo "bueno", que devalúa otras formas de participación política. En el mismo sentido, se asume que estos actores están unificados y son agentes de resistencia y empoderamiento, lo cual implica un desconocimiento - o al menos una subvaloración- de las tensiones y las relaciones de poder que se podrían desarrollar en su interior (Amoore y Langley, 2004, p. 96).

Amoore y Langley (2004) señalan que, para ir más allá en el análisis de este tipo de actores, es necesario indagar sobre los procesos internos de estas redes y coaliciones, los intereses sociales que representan y la forma cómo se construyen sus relaciones de poder. Su propuesta sugiere que es necesario reconocer la naturaleza contradictoria de la sociedad civil global y evidenciar tres aspectos en ella que tienden a ocultarse en los análisis más optimistas:

1. Hay tensiones sobre quién está siendo empoderado y frente a quién se está ejerciendo la resistencia.

2. Los mismos individuos que hacen parte de esta sociedad civil global padecen de contradicciones internas.

3. La sociedad civil global es un espacio para diversas luchas políticas, por lo cual no debe verse como un agente limitado.

Así, lo que se busca es empezar a conocer el proceso a través del cual las redes y los movimientos sociales globales se conforman, visibilizando los conflictos que tal proceso entraña a partir del estudio de un caso particular, con el fin de analizar cómo se construyen los vínculos de solidaridad, los discursos y las prioridades dentro de las agendas de reivindicaciones.

\section{Antecedentes del Foro Social Mundial}

Si bien se argumenta que las capacidades del Estado moderno se han reducido en un contexto de globalización económica y comercial, lo cierto es que estas están lejos de reducirse y lo que ha ocurrido es un cambio en su rol. Autores como Gill (2008) y Sassen (2007) 
argumentan que el Estado neoliberal es un Estado poderoso y grande, cuya tarea fundamental es crear, mantener y vigilar todo el andamiaje institucional para el correcto funcionamiento del mercado. Para ello, se vale de normas formales e informales y prácticas cotidianas de disciplinamiento dentro de la racionalidad política neoliberal (Brown, 2003).

La materialización de ese cambio de rol se dio a través de reformas de ajuste estructural de las economías, de la mano con medidas de liberalización económica, comercial y financiera. Su impacto negativo ha golpeado a amplios sectores de la población mundial, hecho que redunda en que sea posible cuestionar su alcance y efectividad; varios de estos sectores se han organizado y han encontrado espacios para expresar su preocupación por la globalización neoliberal y oponerse expresamente a los organismos financieros internacionales, carentes de prácticas democráticas (Teivainen, 2005; Patterson, 2009).

De esa forma, el mundo se ha convertido en el escenario de un gran número de protestas, cuyos principales interlocutores y antagonistas han sido precisamente los organismos financieros, parte de las fuerzas dominantes (Gill, 2008) del actual sistema global (Sklair, 2003). En noviembre de 1999, tuvo lugar la primera gran megaprotesta durante la cumbre ministerial de la Organización Mundial del Comercio en Seattle, y a partir de allí se han replicado las acciones en reuniones del Fondo Monetario Internacional, del G8 y del Banco Mundial, entre otros. Estas manifestaciones evidenciaron la posibilidad y la potencialidad del movimiento alterglobalización como un nuevo actor social, pero con una característica esencialmente diferenciadora de los otros: su escenario de acción e interlocución no está limitado por las fronteras nacionales (Klein, 2002).

Los orígenes de estas movilizaciones alterglobalización pueden rastrearse hasta 1996, cuando el Ejército Zapatista de Liberación Nacional (EZLN) convocó el I Encuentro Intercontinental por la Humanidad y contra el Neoliberalismo en Chiapas, mejor conocido como I Encuentro Intergaláctico. Allí se reunieron líderes y representantes de diferentes organizaciones y movimientos sociales del mundo, con el fin de construir una alternativa política, social y económica frente a la creciente marginación, fomentada a partir de las tendencias neoliberales y globalizadoras en México y en el resto del mundo (Muñoz, 2003).

Se establecieron mesas temáticas de discusión, mediante las que se encontró una serie de planteamientos comunes: oposición a la guerra, el autoritarismo, la pobreza, la liberalización económica, la discriminación, la marginación y el neoliberalismo, y la defensa de la paz, la democracia, la libertad, la dignidad, la justicia, el trabajo, los derechos sociales, la tolerancia, la memoria y la humanidad (Muñoz, 2003).

Teniendo como punto de partida estos mínimos comunes, los participantes estuvieron de acuerdo en declarar y comprometerse en la construcción de una red global en favor de la humanidad y contra el neoliberalismo. Así, se planteó por primera vez la necesidad de constituir una red global en favor de la humanidad para combatir al neoliberalismo a la 
misma escala; también se acordó que era preciso buscar alternativas frente al modelo económico neoliberal, para lo cual se requerían vínculos y canales de comunicación efectivos entre las diferentes organizaciones sociales (Comité Clandestino Revolucionario, 1996).

Otros antecedentes importantes son la primera campaña contra el Acuerdo Multilateral de Inversiones, impulsada en 1997 dentro de una red de ONG y activistas sociales que se oponían a los efectos de la liberalización económica, principalmente en Europa y en los Estados Unidos (Pleyers, 2010; Seoane y Taddei 2001), y las campañas de Jubileo 2000 durante la década de 1990 para abogar por la condonación de la deuda externa de los países del tercer mundo (Della Porta, 2005; Pleyers, 2010).

Ahora bien, la fuerza del proceso de construcción del movimiento alterglobalización solo se hizo presente en los medios de comunicación después de la Batalla de Seattle, la primera gran megaprotesta en contra de la OMC que tuvo lugar entre el 29 de noviembre y el 3 de diciembre de 1999. A partir de allí, se inició un ciclo de megaprotestas globales que hicieron evidente la existencia de un actor crítico o contestatario frente al proceso de globalización neoliberal, cuyas raíces están en la precaria situación de los derechos humanos, las condiciones laborales y el respeto por el medio ambiente en las actividades de varias compañías transnacionales.

Es importante reiterar que este actor crítico del proceso de globalización neoliberal no está exento de problemas y contradicciones internas. Ejemplo de ello es que el movimiento ha intentado mantenerse como una red sin liderazgo y sin estructura definida, para evitar luchas internas por el poder. Sin embargo, esto y el exceso de autonomía han ido en detrimento suyo, lo cual ha impedido el planteamiento de acuerdos en torno a reivindicaciones y planes de acción (Klein, 2002). Esto, sin embargo, no significa que la diversidad no pueda ser una fuente de inspiración y una fortaleza desde donde construir alternativas.

De igual forma, la ausencia de líderes definidos ha permitido que se constituyan algunos liderazgos de facto y autoproclamados que promueven acciones y estrategias sin el aval de la mayoría de los activistas (Klein, 2002). Aun así, se inició un proceso en el que las diferentes organizaciones de la sociedad civil, provenientes de distintas regiones del mundo, han identificado puntos comunes de demandas y estrategias de movilización, lo cual ha redundado en la necesidad de contar con mayores y más amplios espacios de reunión.

De ahí el surgimiento del FSM como una iniciativa derivada de las megaprotestas globales, que apuntaba a realizar una reunión mundial de sociedad civil, con el fin de llegar a unos mínimos comunes entre todos los participantes de las protestas para formular propuestas alternativas más concretas y retomar el compromiso derivado del I Encuentro Intercontinental por la Humanidad y contra el Neoliberalismo. Dicha reunión debía entonces cumplir con las siguientes características: tener lugar en algún lugar del sur, más exactamente en Porto Alegre; el nombre debía ser Foro Social Mundial, cambiando solo la palabra económico del Foro Económico Mundial, su antagonista; y debía ser organizado 
durante la misma época de este último (Teivainen, 2005). De esa forma, se realizó el I Foro Social Mundial en Porto Alegre en enero de 2001, bajo el lema de "Otro mundo es posible".

\title{
El Foro Social Mundial
}

De acuerdo con la Carta de Principios del FSM (2001a), este se define como:

\begin{abstract}
Un espacio abierto de encuentro para: intensificar la reflexión, realizar un debate democrático de ideas, elaborar propuestas, establecer un libre intercambio de experiencias y articular acciones eficaces por parte de las entidades y los movimientos de la sociedad civil que se opongan al neoliberalismo y al dominio del mundo por el capital o por cualquier forma de imperialismo y, también, empeñados en la construcción de una sociedad planetaria orientada hacia una relación fecunda entre los seres humanos y de estos con la Tierra.
\end{abstract}

Siguiendo con los demás principios de esta carta, se encuentra que el FSM se ha autodefinido como un espacio y, en cierta forma, como una articulación de movimientos y redes sociales, que ha hecho hincapié en el carácter civil y no partidista de su composición. Además, el FSM ha sido leído como una novedad, en la medida en que es incluyente, reúne movimientos de diversa naturaleza, trata temas que atraviesan transversalmente la realidad global y se ha institucionalizado entre actores sociales críticos (De Souza Santos, 2005), a diferencia de las reuniones internacionales sectorizadas de gremios o partidos políticos.

El FSM se ha caracterizado también por no tener acuerdos fundamentales sobre las alternativas que debe proponer y la forma como estas podrían llevarse a cabo, pero las críticas y discusiones en torno a él se han centrado en si este debe quedarse como espacio o transformarse en un actor, qué posición ideológica debe adoptar, señalar la falta de inclusión, representatividad y la estratificación de los participantes, denunciar el predominio de actores como las ONG y la centralidad de América Latina y hacer hincapié en los peligros que puede entrañar la descentralización del evento.

La discusión sobre el rol del FSM como actor o como espacio está relacionada con diferentes tipos de lectura sobre la sociedad civil. Por momentos parece que esta se ha pensado a partir de dos tradiciones diferentes: liberal y neomarxista (Glasius, 2005) o neogramsciana. La tradición liberal fundamenta la sociedad civil en las libertades cívicas y políticas y la deriva de los actores privados (Massal, 2007), mientras que la tradición neomarxista fundamentada en el pensamiento de Antonio Gramsci considera que la sociedad civil está conformada por las instituciones y los individuos que son los encargados de legitimar o no cierto tipo de hegemonía (Cox, 1986; Said, 2002). Desde una lectura liberal, la sociedad civil puede concebirse más como un espacio de discusión y hasta cierto punto de deliberación, mientras que desde una lectura neogramsciana se entiende como un actor con capacidad para cambiar o sostener un estado de cosas dado. 
Esto se refleja en el hecho de que el FSM desempeña tanto funciones deliberativas como de lucha que busca combinar. Así lo sugiere su misma carta de principios que evoca las dos tradiciones de sociedad civil que tienen una idea diferente sobre el quehacer de esta en el espacio global:

La primera es la idea de un espacio deliberativo [...] reflejado en el artículo 1 de la carta que decreta que el FSM debería proporcionar un espacio para la comunicación que es abierto, democrático y libre. La segunda idea se deriva de Gramsci y ve a la sociedad civil como comprometida en una lucha contrahegemónica. (Glasius y Timms, 2005, p. 223)

El FSM se ha planteado como un espacio horizontal y deliberativo, tal como lo propone una lectura liberal, donde no se deciden planes de acción en su nombre. Sin embargo, no todas las organizaciones y los movimientos sociales que allí se reúnen comparten esta posición, y algunas consideran que es necesario adoptar estructuras organizativas que permitan la adopción de mecanismos para asegurar representatividad, responsabilidad y acción, como lo indica la lectura neogramsciana. Esto redunda en conflictos y relaciones de poder entre los actores que buscan una u otra estrategia (Smith et al., 2008).

El FSM también tiene una dimensión utópica que consiste en "la afirmación de la posibilidad de una globalización contrahegemónica. En otras palabras, la utopía del FSM se evalúa más como negatividad (define qué es lo que critica) que como positividad (definir qué es a lo que aspira)" (De Souza Santos, 2005, p. 23). Así, se constituye como un espacio donde se ha buscado establecer una coalición durable, pero que hasta ahora se ha identificado más como una coalición de campaña, dado que allí se han articulado varios actores sociales con diversos enfoques en torno a temas específicos: pobreza, discriminación, exclusión, desigualdad, derechos humanos, etc. El FSM como fuente de movimiento contrahegemónico no podría emerger de no ser por el hecho de que hay una crisis de la hegemonía del siglo XX:

El capitalismo está otra vez difundiéndose como la forma principal de organización socioeconómica, no solo alrededor de los Estados, sino en su interior, en la medida en que la mercantilización profundiza su alcance social y geográfico. Al mismo tiempo, una creciente conciencia planetaria sobre cuestiones ambientales y ecológicas refleja los vínculos complejos entre las fuerzas acumulativas de desarrollo y subdesarrollo económico, la interacción entre campo y ciudad, ricos y pobres, y la guerra y la paz en el orden mundial emergente. (Gill, 1993, p. 6)

El FSM tiene un carácter contrahegemónico que cuestiona el proceso de globalización, que en algunas partes del mundo ha sido hegemónico y en otras dominante. ${ }^{4}$ Esto debido

${ }^{4}$ Para una distinción profunda entre hegemonía (aceptación e interiorización del poder) y dominación (poder por coerción), ver Augelli y Murphy (1993). 
al carácter que tiene la sociedad civil gramsciana de ser el lugar donde los intereses corporativos pueden tornarse universales por medio de reconfiguraciones identitarias, luchas ideológicas y construcciones hegemónicas (Augelli y Murphy, 1993).

Con respecto a la estratificación de los participantes en el FSM, se señala y denuncia la marginalización de ciertos grupos, como jóvenes estudiantes que no tienen acceso a los salones de conferencias vip y el intento por imponer el discurso de determinados sectores a todos los participantes. Hechos que para los críticos más fuertes simplemente hacen parte de la reproducción del proceso de exclusión de la globalización neoliberal en un escenario donde todos los actores sociales tienen como objetivo común la oposición a un discurso determinado, pero no comparten la forma de enfrentarlo ni de alternar esa situación (Teivainen, 2005).

Una crítica puntual que se ha expresado en ese sentido es la de la Asociación Madres de Plaza de Mayo, que decidió abandonar el FSM a partir de 2003:

El Foro tenía tres estados: el de los que mandan, del que se apoderaron los franceses, con alguno que otro de otros países; luego todos los talleres y seminarios, que hacían los filósofos, los intelectuales, los pensadores; y después toda la gente de más abajo, que también íbamos, nos reuníamos y hablábamos, pero en mucha menor cantidad. Porque, en realidad, esta vez se hizo más para escuchar, no para que participáramos los de más abajo. (Bonafini a Fondo, 2002)

De igual forma, se afirma que los eventos que han tenido lugar en Porto Alegre resultaron ser blancos y masculinos (Teivainen, 2005), hecho que refleja una de las tensiones internas que tiene el FSM: inclusión vs. exclusión. Por un lado, el FSM celebra la diversidad, pero tiene serios problemas de representación e inclusión, ya que ha habido una tendencia entre los participantes: nacionalidad (mayoritariamente brasileños), género, idioma y capacidad para acceder a ciertos recursos, como las tecnologías de la información y los viajes internacionales (Glasius y Timms, 2005). ${ }^{5}$

Pese a ello, se sigue reivindicando la diversidad como una de las mayores fortalezas del FSM, que incluye los distintos enfoques para llevar a cabo la movilización y promover la transformación social que coexisten. Así, por ejemplo, hay una distinción entre las organizaciones que adoptan prácticas como la prefiguración, creando y viviendo las transformaciones sociales en la vida cotidiana, y las organizaciones que tienen un enfoque más "estratégico" que dan prioridad a las alianzas con otros actores sociales y políticos para alcanzar sus objetivos (Teivainen, 2012). De igual forma, algunas organizaciones

${ }^{5}$ El FSM posee otro tipo de contradicciones, como su relación con el poder político y las organizaciones sociales de naturaleza más radical; sin embargo, estas no son objeto del presente estudio ([WSF-Discuss] Interview with Teivo Teivainen on the WSF, social movements, and issues of power, 2006). 
están orientadas a partir de reformas, mientras que otras buscan transformaciones más radicales, cercanas a la noción de revolución (Tormey, 2004). Así, es posible, incluso, encontrar en esa misma diversidad un obstáculo para coordinar esfuerzos hacia un mismo norte entre todas las organizaciones.

En el mismo sentido, se plantean las críticas sobre el alcance transformador del FSM y su grado de efectividad. Por ejemplo, García Blanca (2002), miembro de la organización ambientalista catalana Plural-21, señala algunas bifurcaciones:

¿Discurso transformador y práctica reformista? ¿Pretenden las ONG cambiar el mundo o tapar las venas abiertas del Sistema a cambio de subvenciones? ¿Pretenden los Sindicatos cambiar el mundo o meramente multiplicar los puestos de trabajo? ¿Pretenden los Partidos Políticos (PT incluido) cambiar el mundo o simplemente administrarlo?

La orientación ideológica de las organizaciones participantes también da cuenta de las diferencias internas que hay sobre cómo debería funcionar el FMS. Wallerstein (2004) las resume en tres grupos:

La primera proviene de las fuerzas centristas mundiales [...] [que] opinan que el FSM no es ni práctico, ni concreto en su orientación. Este grupo considera que el FSM debe intentar un diálogo con el Foro Económico Mundial y con varias otras instituciones internacionales [...] Una crítica más significativa al FSM proviene de varios grupos que son herederos de la "vieja izquierda" [para los que] el FSM ha estado básicamente subordinado a las ONG occidentales y que era una estructura "objetivamente" contra-revolucionaria [...] El último grupo de críticas proviene desde dentro del mismo FSM. De alguna manera, las críticas internas son versiones diluidas de las críticas externas de las fuerzas centristas mundiales, la "vieja izquierda" hostil y los grupos anarquistas.

Para establecer una coalición durable y responder parcialmente a algunas de estas críticas, se ha buscado diversificar este espacio mediante la organización de foros regionales, nacionales, locales y temáticos, como los de Cartagena en 2003 y Florencia en 2005, donde los actores locales tendrían más espacio y podrían acceder a este más fácilmente que a Porto Alegre. Hacia eso mismo ha apuntado la celebración del FSM en lugares distintos de Brasil y la descentralización de la semana de la movilización en 2008; con ello, el sentido del adjetivo mundial tendría más sentido y les permitiría a los diferentes actores ampliar su base de apoyo e incluir nuevas perspectivas en las discusiones.

Pese a ello, se ha visto en esta iniciativa un peligro contenido, ya que, por un lado, sí se podría ampliar la presencia de otros actores y así ganar legitimidad; pero, por otro, esto podría atomizar el espacio de discusión, con lo cual se regionalizarían 
demasiado los debates y las problemáticas. A partir de esto, se plantea entonces la existencia de una disyuntiva:

Hay un dilema: ¿cómo puede la base del Foro Social Mundial actuar globalmente cuando él es deliberadamente diverso y la prioridad de la mayoría de los participantes es con sus preocupaciones locales y sectoriales? En el Foro Social Mundial descubren que los problemas son globales y aprenden nuevos caminos para actuar localmente, pero no aprenden a confrontar los problemas a escala global. Creen que todos sus esfuerzos sumarán colectivamente una solución global, pero otros argumentan que solo un objetivo fuerte tiene alguna oportunidad de éxito. (Hammond, 2003)

Una vez planteadas las principales críticas que se han dirigido contra el FSM, es importante proponer algunas reflexiones a su alrededor. En primer lugar, es importante tener en cuenta los efectos que este tipo de críticas ha de tener sobre la movilización social transnacional en contra del neoliberalismo en cuanto pueden convertirse en incentivos negativos para esta. En segundo lugar, algunas de ellas presumirían una intencionalidad entre las organizaciones sociales que bien puede no ser tal, dado que la centralidad de ellas o la sobrerrepresentación de algunas regiones del mundo se entienden mejor como un efecto no deseado de las condiciones estructurales del mismo sistema global. Y en tercer lugar, es importante analizar cuidadosamente la diversidad y sus implicaciones, en la medida en que esta puede entenderse como un norte deseable respecto de la participación y representación, como un obstáculo para la construcción de alternativas homogéneas o como una oportunidad para conocer y comprender la pluralidad de visiones de mundo que resisten al neoliberalismo.

Así las cosas, un primer paso en esta amplia reflexión es indagar sobre los fundamentos empíricos de tales críticas. Eso supone una descripción del FSM a partir de las siguientes preguntas orientadoras: ¿qué organizaciones participan masivamente? ¿Qué reivindicaciones específicas terminan siendo generales? ¿Los problemas de qué parte del mundo predominan en la agenda de discusión?

\section{Participación en el Foro Social Mundial}

Con el objetivo de dar cuenta de los actores participantes en el FSM, su tipo de organización y su reivindicación central, se tomaron en cuenta las organizaciones participantes de las versiones 2001 y 2004 y las que convergieron en la semana de movilización de 2008. Dada la imposibilidad de acceder a registros precisos de participantes en el FSM, se tomaron como base las organizaciones que firmaron la Declaración de los Movimientos Sociales en 2001, el Llamamiento de la Asamblea de los Movimientos Sociales en 2004 y el Llamado para un Día de Movilización y Acción Global en 2008. 
Estas organizaciones fueron agrupadas en una base de datos de acuerdo con nombre, versiones en las que participó (de las tres por estudiar), país de origen, autodefinición organizativa y reivindicación central.

Se tomaron en cuenta los siguientes factores: continente y país de origen, tipo de organización, reivindicación central y participación en los tres momentos del FSM. Las categorías de tipo de organización y reivindicación central se construyeron a partir de la autodefinición de los movimientos y las organizaciones, es decir, a partir de cómo ellos se definían, su alcance territorial y sus reivindicaciones. Estos aspectos se analizaron de manera descriptiva con fin de tener más claridad sobre cuáles han sido los temas centrales de discusión entre quienes asisten al FSM y se comprometen con sus declaraciones, qué relación tienen con los temas planteados oficialmente en el FSM, qué tipo de organizaciones participan más, qué países tienen mayor representación y cuál es la frecuencia de participación general en el tiempo.

El I Foro Social Mundial tuvo lugar en Porto Alegre (Brasil), entre los días 25y 30 de enero de 2001, con estimaciones de 20000 participantes. Sus ejes temáticos fueron los siguientes: la producción de riquezas y la reproducción social, el acceso a las riquezas y al desarrollo sustentable, la afirmación de la sociedad civil y los espacios públicos y el poder político y ética en la nueva sociedad.

El IV Foro Social Mundial se realizó en Bombay (India), luego de arduas discusiones entre los sectores que querían llevarlo a más lugares del mundo para diversificarlo y aquellos que querían mantenerlo en América Latina. Se llevó a cabo entre el 16 y el 21 de enero de 2004 y contó con la participación de más de 70 ooo personas. Se manejaron dos tipos de problemáticas: temáticas y transversales. Los ejes temáticos fueron estos: militarismo, guerra y paz; información, conocimiento y cultura; medio ambiente y economía; y exclusión, derechos e igualdad. Los ejes transversales fueron los siguientes: patriarcado; regímenes de castas, racismo y exclusión social; sectarismo religioso, políticas de identidad y fundamentalismo (municipalismo); y militarismo y paz.

Finalmente, la Semana de Acción y Movilización Global tuvo lugar entre el 21 y el 26 de enero de 2008 y finalizó con un gran día de acción global. Se reivindicó la lucha en contra del neoliberalismo, la guerra, el colonialismo, el racismo y el patriarcado que generan violencia, la explotación, la exclusión, la pobreza, el hambre, el desastre ambiental y la negación de los derechos humanos. Participaron 58 organizaciones que se adhirieron a la convocatoria inicial en 2007.

Una primera aproximación a la conformación del FSM muestra cómo no hay una correspondencia entre las organizaciones y los movimientos sociales participantes y aquellos que firmaron sus declaraciones. Así, de acuerdo con cifras oficiales del FSM en su primera versión, participaron 500 organizaciones, mientras que tan solo 171 firmaron su declaración final. En 2004, se registraron 1653 organizaciones y movimientos 
sociales y tan solo 115 firmaron la declaración de esta versión (tabla 1). Esta relación es difícil de hallar en 2008, ya que no hubo un proceso de registro de los participantes, debido al carácter descentralizado del evento.

\section{Tabla 1. Actores y frecuencia de participación en el Foro Social Mundial}

\begin{tabular}{|l|r|}
\hline \multicolumn{1}{|c|}{ Año } & Actores \\
\hline 2001 & 150 \\
\hline 2004 & 53 \\
\hline 2008 & 50 \\
\hline 2001,2004 y 2008 & 12 \\
\hline 2001 y 2008 & 4 \\
\hline 2004 y 2008 & 45 \\
\hline 2001 y 2004 & 5 \\
\hline Total & $\mathbf{3 1 9}$ \\
\hline
\end{tabular}

Fuente: elaboración propia

Surge entonces la pregunta de por qué esta falta de correspondencia y, aún más importante, por qué la disminución de esta en 2004. ¿Está esto relacionado con las críticas reiterativas sobre la conformación del FSM y la centralidad de ciertos actores, provenientes de organizaciones y movimientos sociales que participaron en alguna de sus versiones, pero que nunca han firmado sus declaraciones? En otras palabras, ċlas posiciones críticas que algunas organizaciones han tenido frente al FSM son producto de su participación en él y posteriormente argumentos suficientes para abstenerse de firmar sus declaraciones finales?

En ese mismo sentido, es importante conocer quiénes han sido los actores que han suscrito las dos declaraciones y el llamado. Tal y como se observa en la tabla 1, solo hay 12 organizaciones y movimientos que participaron en los tres momentos estudiados aquí. La continuidad más fuerte es la que se dio entre 2004 y 2008, cuando 45 organizaciones suscribieron tanto la declaración como la convocatoria.

Dentro de las 12 organizaciones que suscribieron los documentos de los tres momentos estudiados aparecen ATTAC-Francia y el MST-Brasil, movimientos fundadores del FSM y objetos de muchas de las críticas sobre la concentración de poder en la toma de decisiones. Esto es un buen indicador de que los actores que iniciaron el proceso se mantienen en él y de que se comprometieron con los acuerdos a los que allí se llegaron. Por otro lado, es posible argumentar que estos actores, tan comprometidos como se han manifestado, orientan tácita o explícitamente algunas de las discusiones y los compromisos finales a los que se adhieren algunos de los participantes del FSM.

El planteamiento general de la Declaración de los Movimientos Sociales de 2001 sostuvo que las organizaciones y los movimientos sociales que la suscribieron: 
Estamos en contra de la hegemonía del capital, la destrucción de nuestras culturas, la monopolización del conocimiento y los medios de comunicación de masas, la degradación de la naturaleza y la deterioración de la calidad de vida a través de las manos de las corporaciones transnacionales y de las políticas antidemocráticas [...] Demandamos un sistema de comercio justo que garantice el pleno empleo, la seguridad alimentaria, términos de intercambio equitativos y prosperidad local. El "libre comercio" no es tan libre [...] Convocamos a apoyar las movilizaciones contra la creación del Área de Libre Comercio de las Américas (ALCA), una iniciativa que significa la recolonización de la región y la destrucción de los derechos humanos fundamentales, sociales, económicos, culturales y ambientales.

(Foro Social Mundial, 2001b)

Esta declaración apuntó, entonces, a recalcar aquello a lo que las organizaciones y los movimientos se estaban oponiendo y lo que estaban exigiendo por parte de sus antagonistas: Foro Económico Mundial y organismos financieros internacionales. Las exigencias de estos actores se quedaron en un plano demasiado amplio y no propusieron mecanismos concretos para materializarlas ni por parte suya ni de sus antagonistas. De igual forma, es interesante señalar cómo el Área de Libre Comercio de las Américas (ALCA), asunto regional y de importancia casi que exclusiva para los actores sociales de las Américas, quedó plasmado en un documento de carácter global, donde organizaciones y movimientos sociales de otras partes del mundo se comprometieron a luchar en su contra.

Surge entonces el interrogante de por qué hacer explícita la lucha en contra del ALCA y omitir procesos similares en otras partes del mundo. La coyuntura de negociación y el consecuente establecimiento de redes en contra del libre comercio en las Américas pueden explicar el porqué de la centralidad y la explicitud del ALCA como blanco de lucha. No obstante, esto no es suficiente para dar razón sobre la ausencia de otros procesos de libre comercio en el mundo (establecidos o en negociación), y es allí donde la centralidad de los movimientos y las organizaciones latinoamericanos, tanto en la organización como en la participación en el FSM, podría tener un mayor poder explicativo, más si se tiene en cuenta que el Llamamiento de la Asamblea de los Movimientos Sociales de 2004 incluyó la prioridad de la lucha contra todos los acuerdos de libre comercio, con lo cual amplió su espectro más allá de América, y procesos como el Acta de Crecimiento y Oportunidad Africana y la Asociación de Naciones del Sureste Asiático.

$\mathrm{Al}$ revisar los datos generales de las organizaciones y los movimientos sociales que firmaron los tres documentos, se encontró que América Latina es la región del mundo de la cual provienen la mayor cantidad de actores, que junto con los provenientes de América del Norte logran sumar cerca de $45 \%$ del total, que demuestra su importancia representativa y deliberativa en la discusión y definición de temas y compromisos. 
Las organizaciones y los movimientos sociales europeos y latinoamericanos son los que se comprometieron con estas declaraciones en mayor medida. Sin embargo, al observar los datos más específicamente y tomando en cuenta los países de origen, se encuentra que las organizaciones brasileñas predominan en el proceso del FSM, seguidas de aquellas organizaciones que definen el alcance de sus reivindicaciones y de sus prácticas de movilización social como globales. En la figura 1, es posible observar esto con mayor claridad.

\section{Figura 1. Procedencia de las organizaciones participantes en el Foro Social Mundial.}

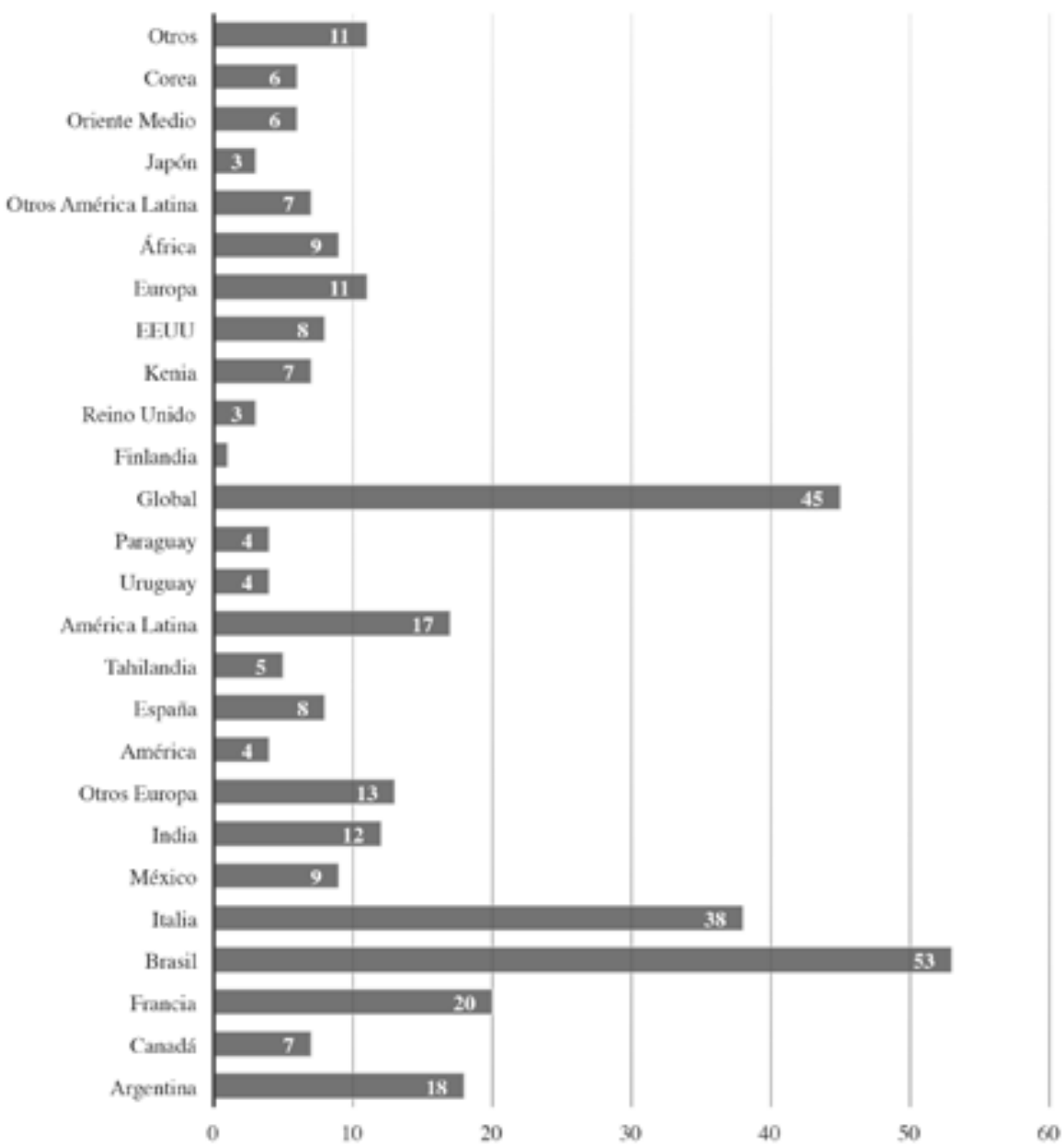

Fuente: elaboración propia

En cuanto a las reivindicaciones de las organizaciones participantes, se encuentra que los ejes centrales giran en torno al empleo digno, la lucha contra la globalización 
neoliberal y la distribución de la riqueza; hecho que sí corresponde con los ejes temáticos planteados por la organización del FSM en los tres momentos estudiados. Pese a ello, la reivindicación de empleo digno no es explícita en ninguno de los tres momentos, y los reclamos sobre distribución de la riqueza o en contra de la globalización son más importantes; también es preciso anotar que se encuentra una amplia variedad de reivindicaciones particularistas o planteadas solo por una o dos organizaciones del total de la muestra que no pueden ser agrupadas, como la unidad cristiana.

Otro aspecto importante en este sentido es la categoría "equidad de género", que comprende reivindicaciones ligadas a la reforma agraria, los derechos de la mujer trabajadora o la relación género-libre comercio. Estas reivindicaciones habrían podido ser agrupadas con las de otras organizaciones relacionadas con las problemáticas señaladas, pero se habría invisibilizado la existencia de una mirada de género en estos temas.

Por otro lado, una de las críticas que se realiza en contra del FSM desde perspectivas de izquierda radical o anarquistas gira en torno a la centralidad que las ONG han tenido en el proceso de convocatoria y de decisión. De ahí, la necesidad de revisar qué tipo de organizaciones y movimientos sociales han firmado los tres documentos estudiados. Se identificaron 14 tipos de organizaciones a partir de la autodefinición de los actores, teniendo en cuenta la misma salvedad de las reivindicaciones frente a la dificultad de agrupar o categorizar algunas de ellas.

Si bien las ONG tienen una presencia fuerte en los tres momentos estudiados, no son los actores con mayor participación. La figura 2 muestra que las organizaciones con mayor participación son las que se definen como redes sociales, seguidas de los movimientos sindicales, las ONG y los grupos académicos. Sin embargo, esto no sugiere que las ONG no gocen de una posición dominante en la deliberación de temas o que sus reivindicaciones no logren posicionarse con mayor fuerza que las de otros actores. En el mismo sentido, muchas de las organizaciones que se autodefinen como redes sociales pueden ser redes de ONG o contar con alguna organización de este tipo entre sus miembros. 
Figura 2. Tipos de organización.

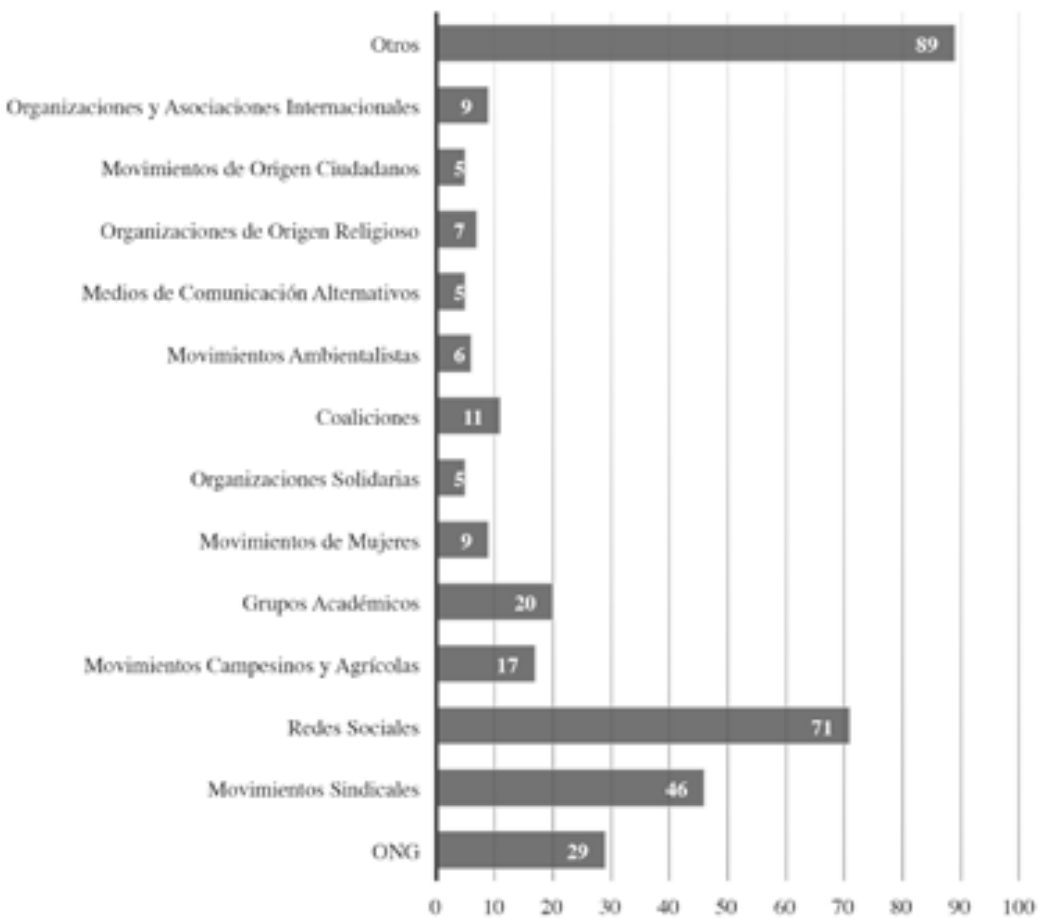

Fuente: elaboración propia

Hasta ahora esta es la caracterización que se puede hacer del FSM como proceso general. A continuación, se revisan las relaciones entre diferentes aspectos, como el continente y el país de procedencia, las reivindicaciones centrales, el tipo de organización y la frecuencia de participación, que se analizan con el fin de lograr una caracterización más allá de la panorámica ofrecida hasta ahora y establecer relaciones más profundas que permitan fundamentar o contradecir las críticas ya citadas al FSM como proceso y como actor.

\section{Relaciones entre actores, temas y participación}

A partir de la presentación general de los tres momentos analizados del FSM, se presentan algunos datos concretos, como la centralidad de reivindicaciones, la participación de determinados tipos de organización y la representatividad por nacionalidad de las organizaciones. Esto sirve para reforzar el argumento sobre el peso que han tenido las organizaciones y los movimientos de regiones del mundo como América Latina en la definición de tema y acciones puntuales.

Como se señaló, en términos generales, los países de procedencia de la mayor parte de las organizaciones y los movimientos sociales son Brasil, Italia, Francia 
y Argentina; sin embargo, este comportamiento no se sostiene en el tiempo. En la tabla 2, se observa cómo en 2001 se empezó con una participación significativa de las organizaciones de todos los países mencionados y cómo esta decrece en los otros dos momentos estudiados, hecho que sugeriría en una primera aproximación que la participación y el compromiso general de los actores provenientes de esos países con el FSM han disminuido en sus diez años de vida.

Tabla 2. Relación país-participación en el Foro Social Mundial

\begin{tabular}{|c|c|c|c|c|c|c|c|c|}
\hline \multicolumn{9}{|c|}{ Versiones Foro Social Mundial } \\
\hline País & 2001 & 2004 & 2008 & $\begin{array}{c}2001,2004 \\
\text { y } 2008\end{array}$ & \begin{tabular}{|c|}
2001 \\
y 2008 \\
\end{tabular} & \begin{tabular}{|c|}
2004 \\
y 2008 \\
\end{tabular} & \begin{tabular}{|c|}
2001 \\
y 2004 \\
\end{tabular} & Total \\
\hline Argentina & 15 & 1 & 0 & 2 & 0 & 1 & 0 & 19 \\
\hline Canadá & 1 & 3 & 0 & 0 & 0 & 1 & 1 & 6 \\
\hline Francia & 11 & 2 & 3 & 1 & 0 & 1 & 0 & 18 \\
\hline Brasil & 39 & 0 & 3 & 2 & 1 & 5 & 0 & 50 \\
\hline Italia & 34 & 1 & 1 & 0 & 1 & 2 & 0 & 39 \\
\hline México & 7 & 0 & 1 & 0 & 0 & 0 & 1 & 9 \\
\hline India & 6 & 1 & 4 & 0 & 0 & 0 & 0 & 11 \\
\hline América & 0 & 1 & 0 & 0 & 1 & 1 & 1 & 4 \\
\hline España & 5 & 0 & 3 & 0 & 0 & 0 & 0 & 8 \\
\hline América Latina & 3 & 5 & 0 & 0 & 0 & 6 & 0 & 14 \\
\hline Global & 2 & 17 & 10 & 3 & 0 & 12 & 0 & 44 \\
\hline Reino Unido & 0 & 1 & 1 & 0 & 0 & 1 & 1 & 4 \\
\hline Estados Unidos & 1 & 3 & 3 & 0 & 0 & 1 & 0 & 8 \\
\hline Europa & 0 & 4 & 3 & 0 & 0 & 4 & 0 & 11 \\
\hline África & 0 & 4 & 4 & 1 & 0 & 3 & 1 & 13 \\
\hline Oriente Medio & 0 & 3 & 2 & 0 & 0 & 2 & 0 & 7 \\
\hline Otros Europa & 6 & 1 & 2 & 1 & 0 & 3 & 0 & 13 \\
\hline Otros América Latina & 11 & 1 & 1 & 0 & 0 & 2 & 0 & 15 \\
\hline Otros & 9 & 5 & 2 & 2 & 1 & 0 & 0 & 19 \\
\hline Kenia & 0 & 0 & 7 & 0 & 0 & 0 & 0 & 7 \\
\hline Total & 150 & 53 & 50 & 12 & 4 & 45 & 5 & 319 \\
\hline
\end{tabular}

Fuente: elaboración propia

Llama particularmente la atención el caso de las organizaciones y los movimientos italianos, que empezaron en 2001 como los segundos más participativos, después de los brasileños, y terminan con una presencia casi que marginal. De igual forma, ninguno de estos actores tiene presencia sostenida en los tres momentos estudiados, lo cual conlleva preguntarse qué ocurre con ellos. 
Algunas críticas provenientes de ciertos movimientos italianos apuntan a resaltar la centralidad negativa de los movimientos y las organizaciones latinoamericanos, así como de algunos de los Gobiernos de izquierda de la región. De acuerdo con Maidanik (2006),

con el crecimiento del liderazgo de la izquierda, principalmente en el mundo latinoamericano, y el consecuente aumento de la participación de los exponentes contrarios a la derecha, el principio de autodeterminación del FSM, en el que ninguno puede tomar decisiones en nombre de otros ni pretender predominar en las discusiones, puede perderse. (citado por Chicayban y Della Pietra, 2006)

No obstante, es necesario resaltar el hecho de que las organizaciones no circunscritas a un espacio geográfico nacional aumentaron su participación a lo largo de los tres momentos. Así, las organizaciones y los movimientos que definieron su alcance, respecto de reivindicaciones y prácticas, como global, latinoamericano y europeo, mostraron una tendencia de participación creciente. Frente a ello es válido entonces indagar sobre si las organizaciones que en un primer momento participaron y se comprometieron de manera individual en 2001 empezaron a formar parte de redes transnacionales o de movimientos globales, manteniendo su presencia y compromiso con el FSM, pero de manera colectiva. ${ }^{6}$

La procedencia de los movimientos y las organizaciones con relación a sus reivindicaciones es un dato que debe ser analizado, ya que permite ver, por ejemplo, si una mayor presencia o participación en el compromiso del FSM equivale a que sus reivindicaciones están incluidas en estos. Un primer acercamiento está dado por el tipo de reivindicaciones que tienen las organizaciones por continente o región. Frente a ello hay dos elementos básicos que vale la pena resaltar: 1) las reivindicaciones de las organizaciones y 2) los movimientos europeos están dentro de las 16 categorías establecidas en este trabajo, mientras que las de las latinoamericanas no caben plenamente dentro de estas (figura 3).

${ }^{6}$ Esta sugerencia va más allá del alcance del presente trabajo, por lo cual sería prudente explorarla en trabajos posteriores. 
Figura 3. Relación entre reivindicaciones y continente.

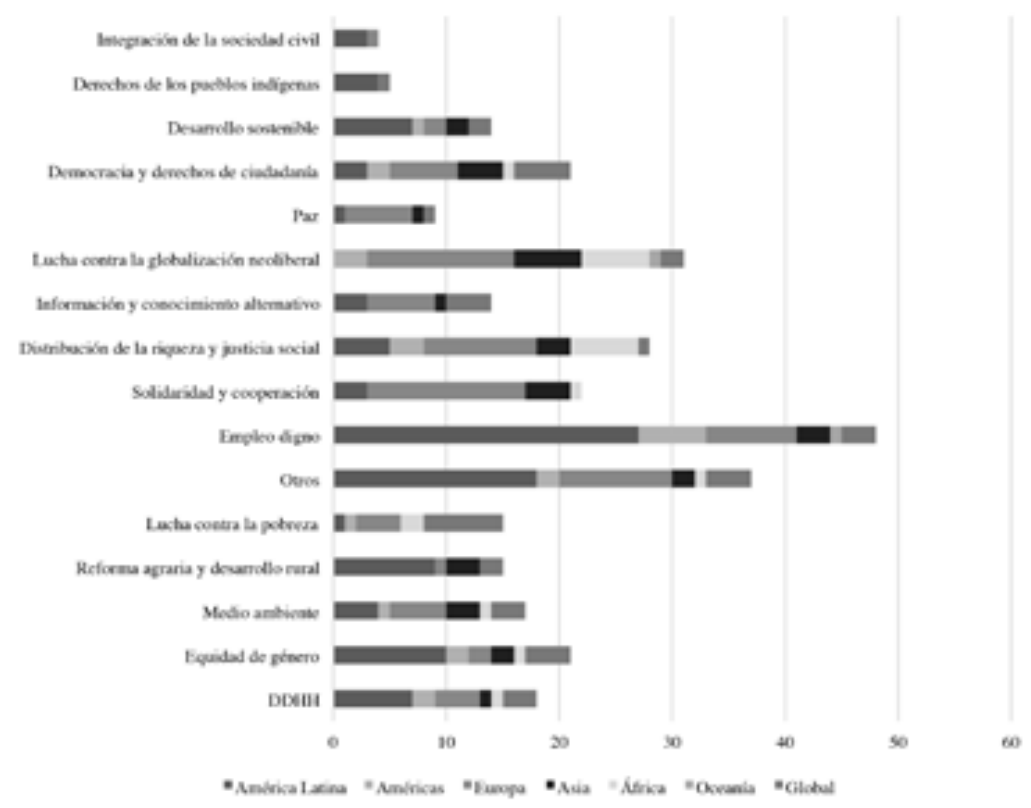

Fuente: elaboración propia

Es interesante anotar que, por ejemplo, la lucha contra la globalización neoliberal no aparece como una reivindicación central para la mayoría de las organizaciones latinoamericanas. Esto es especialmente relevante si se tiene en cuenta que esta reivindicación ha sido el motor de todo el proceso del movimiento alterglobalización y de los movimientos que han hecho parte de este. De ahí que la ausencia de reivindicaciones explícitas de este tipo entre los movimientos y las organizaciones latinoamericanas llame la atención, especialmente si se tiene en cuenta la centralidad que se les ha otorgado a estas organizaciones dentro del FSM. Las reivindicaciones de estas últimas están ligadas a temas más específicos, como el empleo digno, la reforma agraria, los derechos humanos y la equidad de género; problemáticas fundamentales en la región a lo largo de todo el siglo XX y que se profundizaron en la década de 1990 gracias a las reformas de ajuste estructural.

En América Latina, "cuando los ciudadanos protestan contra aspectos del nuevo modelo, sobresalen especialmente al no desafiar al neoliberalismo en abstracto [...] se rebelan contra el neoliberalismo según como él los afectó en su día a día” (Eckstein, 2006, p. 35), lo cual les da un asidero más práctico a los movimientos y las organizaciones de la región. Esto no quiere decir que en la región no se haya buscado combatir la globalización o el neoliberalismo, sino que se ha hecho de otra manera: las reivindicaciones de los 
movimientos y las organizaciones latinoamericanos sí apuntan a combatir la globalización y el neoliberalismo, solo que en las formas específicas que estos dos procesos han adoptado en la región y han perjudicado a los distintos sectores de la sociedad.

En cuanto a las reivindicaciones centrales y la relación con el país de origen, se encuentra que las reivindicaciones de las organizaciones brasileñas e italianas están relacionadas con el empleo digno, la distribución de la riqueza y la solidaridad. De la misma forma, las reivindicaciones de las organizaciones francesas, que junto con las brasileñas son criticadas y acusadas de concentrar el FSM, están ligadas a la solidaridad con otras partes del mundo, especialmente el tercer mundo.

Las organizaciones globales, latinoamericanas, europeas y africanas se concentran en la lucha contra la pobreza, la redistribución de la riqueza y la justicia social y la democracia. Las organizaciones globales también presentan reivindicaciones ligadas al medio ambiente en una proporción importante; sin embargo, las otras organizaciones transnacionales no tienen reivindicaciones explícitamente medioambientales, aunque en el caso de América Latina algunas se vinculan con el desarrollo sostenible.

La reforma agraria y los derechos de los pueblos indígenas, temas cruciales para América Latina, solo aparecen como centrales en el caso de México, Ecuador y Colombia. Para el caso brasileño, la reforma agraria y el desarrollo rural son reivindicaciones importantes, aunque no centrales y manifestadas, sobre todo, por el Movimento dos Trabalhadores Rurais Sem Terra (MST) y organizaciones de mujeres campesinas.

Finalmente, las reivindicaciones de equidad de género no tienen tanta presencia en la agenda general como las mencionadas, pero son el eje de organizaciones argentinas, francesas, brasileñas, globales, latinoamericanas y africanas. Este hecho sugiere la necesidad de un enfoque de género, no solo en las reivindicaciones más generales, sino también en el proceso mismo del FSM, aspecto que ha concentrado algunas de las críticas que se hacen a su alrededor.

Se observa también una relación entre las reivindicaciones de las organizaciones y las versiones del FSM. Se puede afirmar que la redistribución de la riqueza, la lucha contra la globalización, la lucha contra la pobreza, los derechos humanos, la equidad de género y la democracia son centrales a lo largo de los tres momentos estudiados, aunque obedezcan a organizaciones que solo participaron en uno de ellos.

El empleo digno y la reforma agraria, si bien están presentes en los tres momentos, solo fueron centrales durante el I Foro Social Mundial, con lo que se puede plantear una relación también con la localización de este tipo de reivindicaciones en Brasil y la masiva participación de organizaciones provenientes de este país y del resto de América Latina en el primer momento (tabla 2). Esto sugiere, entonces, que los reclamos y la lucha contra la globalización se plantean tanto en términos abstractos como en términos específicos. 
La figura 4 permite observar que en 2001 las organizaciones con reivindicaciones categorizadas como "otros" tienen una presencia importante, mientras que pierden peso relativo en los dos momentos siguientes. Existen dos posibles conclusiones al respecto: hay una mayor articulación de los temas y de las problemáticas particularistas y dispersas a lo largo del proceso del FSM o las organizaciones y los movimientos que encontraron sus reivindicaciones demasiado específicas con respecto a las de los demás dejaron de participar en un proceso que encontraron inadecuado para sus intereses.

\section{Figura 4. Relación reivindicación central y versión del Foro Social Mundial.}

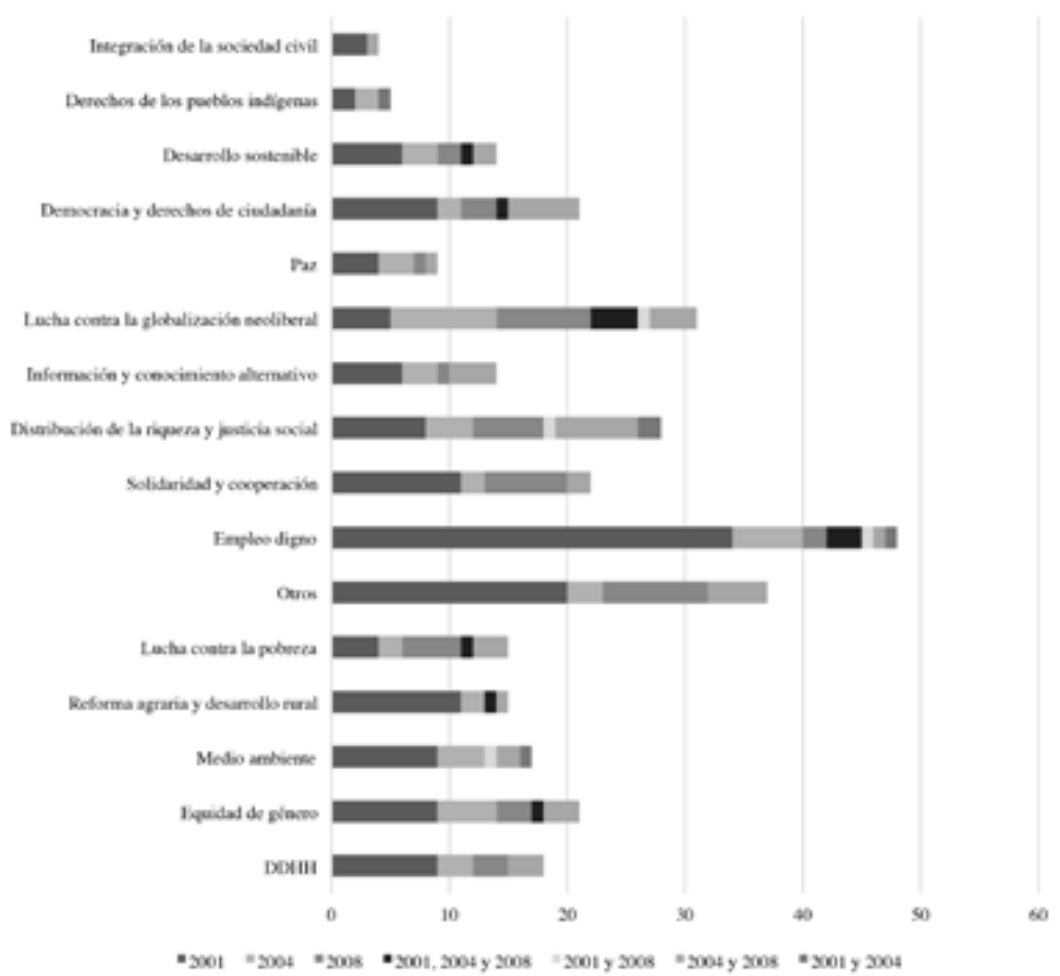

Fuente: elaboración propia

Finalmente, la crítica que señala las ONG como los actores dominantes dentro del FSM es parcialmente desvirtuada, pero aún es necesario saber qué tipo de reivindicaciones tienen las organizaciones y los movimientos que aparecen de manera más reiterativa en los tres momentos y cuál es su peso y participación relativa en cada uno de ellos.

La figura 5 permite ver que las ONG son centrales a lo largo de 2001, pero dejan de serlo en los dos momentos siguientes, así como los movimientos sindicales. El 
proceso de las redes sociales, por su parte, es inverso, que evidencia que en 2001 tienen una mayor participación en la firma de documentos finales que sostienen hasta 2008.

\section{Figura 5. Tipo de organización y participación en el Foro Social Mundial.}

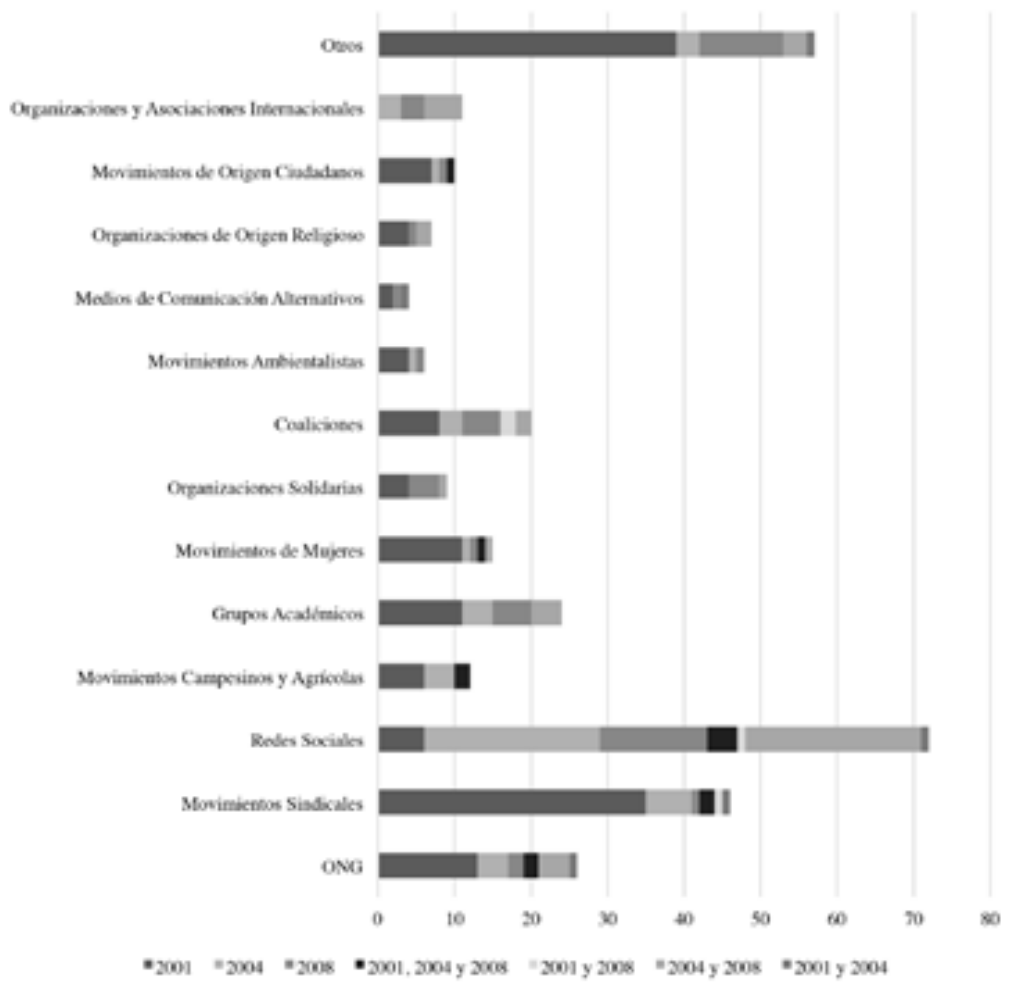

Fuente: elaboración propia

El crecimiento de la participación de organizaciones como las redes sociales y las coaliciones a lo largo del proceso se suma al argumento esbozado previamente sobre la posibilidad de una mayor articulación de organizaciones y de reivindicaciones en el FSM; algo que de ser así sugeriría un avance en la gestación de procesos contrahegemónicos desde una parte de la sociedad civil que se puede pensar a sí misma en términos transnacionales.

Ahora bien, la relación entre el tipo de organización y las reivindicaciones centrales permite un acercamiento particular a la relevancia de ciertas organizaciones y movimientos dentro del proceso del FSM en el momento de debatir y decidir cuáles son los ejes de lucha y las reivindicaciones centrales con los que los actores se comprometen a lo largo de todo el proceso. 
En la figura 6, se puede observar que las reivindicaciones más importantes para las ONG son los derechos humanos, la lucha contra la pobreza y la solidaridad y la cooperación. Estas tres reivindicaciones están presentes en los tres momentos estudiados, pero no hacen parte de los componentes centrales de ninguno de los tres documentos finales. Estos documentos tienen como eje central la lucha contra la globalización neoliberal y los acuerdos de libre comercio, así como la exigencia de la distribución de la riqueza y la justicia social, aunque se haga referencia a temas como la lucha contra la pobreza o la defensa de la democracia y los derechos humanos.

Figura 6. Tipo de organización y reivindicaciones.
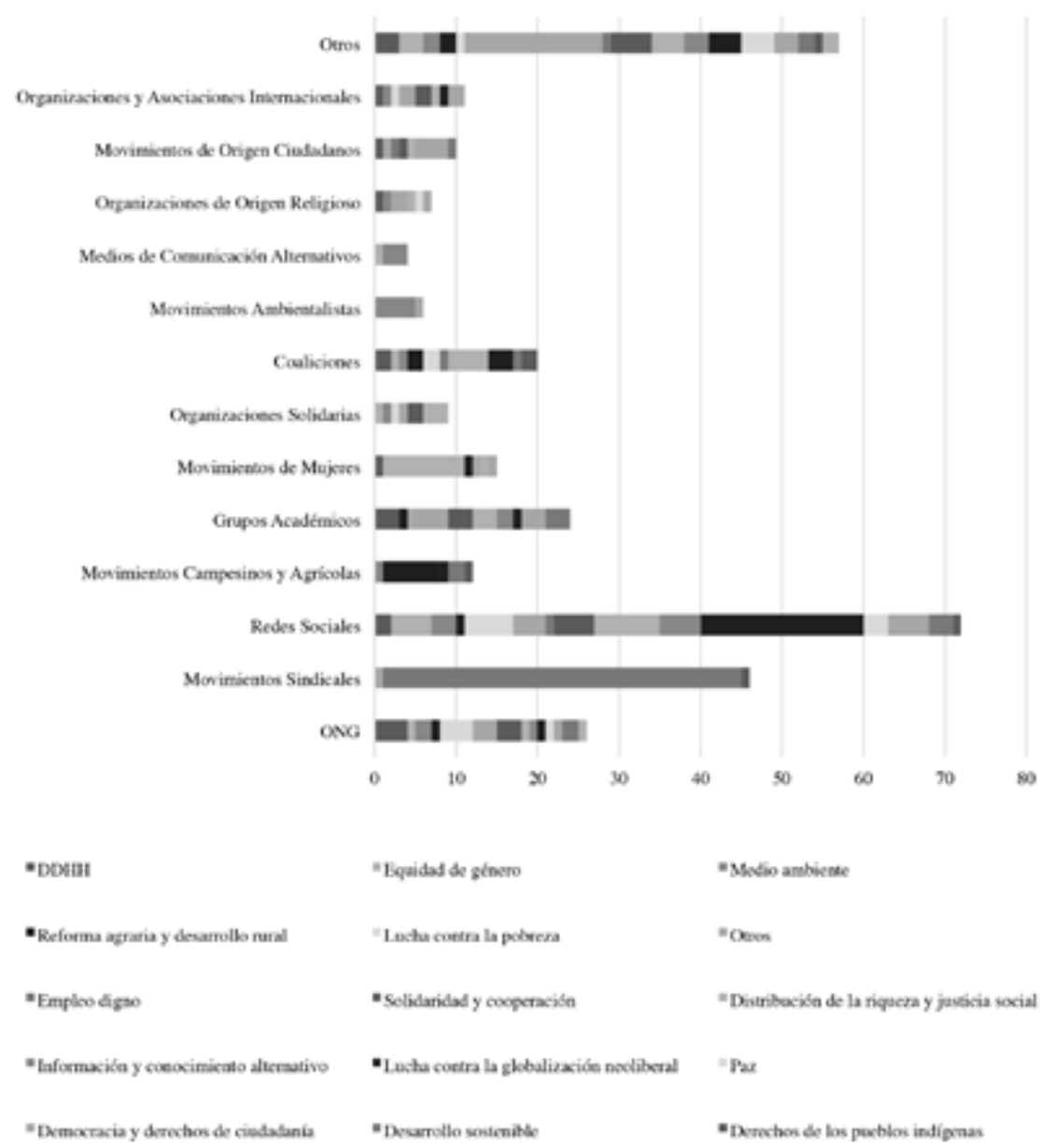

"totegraciob de la soniodad sivit

Fuente: elaboración propia 
En ese sentido, son las redes sociales las que tienen lo que se podría denominar una representación más importante de sus reivindicaciones en estos documentos. La distribución de la riqueza es la segunda reivindicación más importante para este tipo de actores, lo cual es un indicador importante de la relación que puede existir entre los compromisos y acuerdos planteados en los documentos finales del FSM y quienes suscriben dichos documentos.

Quienes firman los documentos y se comprometen con determinadas acciones son los que ven que sus reivindicaciones y demandas están representadas allí planteadas en clave de lucha global. También podría pensarse que son estos actores los que adquieren un compromiso mayor con el proceso del FSM y por tanto son quienes discuten con mayor frecuencia y regularidad las posibles alternativas y los posibles acuerdos a los que allí se puede llegar, y por ende logran poner sus propias preocupaciones como parte de las de otras organizaciones y movimientos sociales del mundo.

Hasta ahora esta descripción sirve para desmitificar y reforzar algunas de las críticas más recurrentes sobre el FSM. Se identifican algunos temas centrales y actores que se presentan como dominantes frente a otros con relación a lo anterior. Sin embargo, más que satisfacer dudas o responder preguntas, se generan varias preocupaciones con respecto al papel desempeñado por determinadas organizaciones y con relación a su nacionalidad y reivindicaciones centrales. Estas cuestiones se plantean en la siguiente sección, con el fin de que sean tenidas en cuenta como posibles recomendaciones para ampliar este trabajo y realizar nuevas investigaciones.

\section{Reflexiones finales}

En este artículo, se buscó caracterizar a los actores que participaron en tres momentos del FSM que manifestaron su compromiso con el proyecto allí planteado a partir de la firma de sus declaraciones y convocatorias, con el propósito de indagar sobre el sustento empírico de varias de las críticas que se le han formulado en la literatura sobre el tema. Se logró identificar los tipos de organización, sus nacionalidades y sus reivindicaciones centrales mediante un proceso de clasificación y categorización.

Pese a ello no fue posible distinguir a los actores individualmente -319 organizaciones participantes-dentro del análisis, aunque sí se identificaron algunas tendencias que dan cuenta del peso de determinados tipos de organización (redes sociales) y de ciertas regiones del mundo (América Latina). Esto, a su vez, sirve para controvertir críticas como la centralidad de las ONG y para reforzar otras como el predominio de organizaciones y movimientos latinoamericanos, específicamente brasileños.

En ese mismo sentido, la "globalidad" del FSM también puede ponerse en tela de juicio, ya que, si bien hay organizaciones y movimientos de los cinco continentes comprometidos en los tres documentos, hay un desequilibrio en cuanto a su número. Se 
encuentra que el FSM es prácticamente un evento europeo y latinoamericano, donde organizaciones asiáticas y africanas tienen una presencia inferior no solo en número, sino también en cuanto a sus preocupaciones e intereses, como se evidenció en el caso del peso de la lucha contra el ALCA en la agenda de las primeras versiones del FSM.

Estos primeros hallazgos dan cuenta de un FSM en el que hay un tipo de actores predominantes y unos temas que logran posicionarse como más importantes o más urgentes frente a otros, lo cual permite ver algunos de los problemas que se han omitido en el estudio de la sociedad civil global y de las redes transnacionales, a saber: no todos los actores son igualmente "empoderados", adelantan luchas en nombre de todos pero representan solo a una porción de la sociedad, hay relaciones internas de poder y ausencia de mecanismos de verificación o validación para los procesos que se supone deberían iniciarse a partir de los compromisos adquiridos.

Los hallazgos de este trabajo constituyen un primer paso para encontrar y conocer a fondo los problemas señalados. Es recomendable realizar ejercicios similares con las versiones del FSM que quedaron fuera de este estudio por dificultades de acceso a la información, ya que ello permitiría tener una visión más completa y general de las características y tendencias identificadas.

De igual forma, estos hallazgos preliminares suscitan nuevos interrogantes que apuntan a un conocimiento más específico y detallado de las razones de los actores participantes para mantenerse o abandonar el proceso del FSM, ya que esto puede contribuir a identificar con mayor claridad las tensiones que se han gestado en el proceso de conformación de un proceso más amplio, como el del movimiento alterglobalización. Asimismo, es pertinente indagar sobre si algunos de estos actores ha entrado a formar parte de las redes y coaliciones (como ha supuesto en parte este trabajo), dado que esto sugeriría que las tensiones se estarían reduciendo para una articulación de movimientos y organizaciones que logran identificarse entre sí, hasta el punto de construir una solidaridad compartida.

Esto requiere la realización de trabajos más profundos - estudios de caso- con los actores identificados como comprometidos en los primeros momentos que dejaron de aparecer en el proceso, teniendo como punto de partida los datos y las relaciones planteadas de manera preliminar en este trabajo y estableciendo si dichos actores desaparecieron porque abandonaron el proceso o porque empezaron a formar redes y coaliciones sociales a partir de su primera participación en el FSM.

Pese a ello, factores como los foros regionales, locales y temáticos, la descentralización en eventos de movilización y la organización del FSM en distintas regiones del mundo contribuyen a expandir la resistencia contra el neoliberalismo en clave global, en la medida en que abre espacio para que diferentes organizaciones alrededor del mundo hagan presencia física en sus procesos de discusión y debate. El hecho de realizar el foro en diferentes ciudades del sur global permite que organizaciones, movimientos y 
activistas provenientes de ellas participen en sus espacios, independiente de si hay o no un predominio de organizaciones latinoamericanas y europeas.

De ahí que sea posible afirmar que el FSM es uno de los sitios idóneos para el desarrollo ideológico y de alternativas de política contra el neoliberalismo (Steger, Goodman y Wilson, 2013). Este constituye un espacio abierto de construcción de alternativas a la globalización neoliberal en el que participan comunidades empoderadas, grupos de educación popular y grupos consejeros en temas puntuales (Worth, 2013), que no solo están comprometidos con la idea de que otro mundo es posible, sino que también han logrado implementar diferentes formas de organización y producción por fuera de los esquemas de democracia representativa y economía de mercado.

\section{Referencias}

Amoore, L. y Langley, P. (2004). Ambiguities of global civil society. Review of International Studies, 3o(1), 89-110.

Augelli, E. y Murphy, C. N. (1993). Gramsci and international relations: A general perspective with examples from recent US policy toward the Third World. En G. Stephen (ed.), Gramsci, historical materialism and international relations (pp. 127-147). Cambridge: Cambridge University Press.

Bonafini a Fondo. Entrevista a la Presidenta de la Asociación Madres de Plaza de Mayo (15 febrero 2002). En Paginadigital. Recuperado de http://www.paginadigital. com.ar/articulos/2002rest/2002seg/entrevistas/ebe15-2.html

Brown, W. (2003). Neo-liberalism and the end of liberal democracy. Theory \& Event, 7(1).

Cepeda Másmela, C. (2015). Resistencias contra el neoliberalismo: entre lo local y lo global (Tesis de doctorado, Universidad de los Andes, Bogotá, Colombia).

Cox, R. (1986). Social forces, states and world orders: Beyond international relations theory. En R. O. Keohane (ed.), Neorrealism and its Crtics. Nueva York: Columbia University Press.

Della Porta, D. (2003). Cosa è un movimento “globale”. En New global.[chi sono e cosa vogliono i critici della globalizzazione]. Boloña: Il Mulino.

Della Porta, D. (2005). The social bases of the global justice movement: Some theoretical reflections and empirical evidence from the First European Social Forum. Ginebra: Institut de recherche des Nations Unies pour le Développement Social.

Della Porta, D., Andretta, M., Mosca, L. y Reiter, H. (2006). Globalization from below: Transnational activists and protest networks. Minneapolis: University of Minnesota Press. 
Comité Clandestino Revolucionario Indígena (CGEZLN) (1996). Segunda Declaración de La Realidad. Recuperado de http://bibliotecavirtual.clacso.org.ar/ar/libros/ osal/osal3/documentos1.pdf

De Souza Santos, B. (2005). Foro Social Mundial: manual de uso. Barcelona: Icaria.

Eckstein, S. (2006). Urban resistance to neoliberal democracy in Latin America. Colombia Internacional, 63, 12-39.

Enlace Zapatista (3 agosto 1996). Segunda Declaración de La Realidad por la Humanidad y contra el Neoliberalismo. Recuperado de http://enlacezapatista.ezln. org.mx/1996/o8/o3/segunda-declaracion-de-la-realidad-por-la-humanidady-contra-el-neoliberalismo/

Florini, A. (2003). Who does what? Collective action and the changing nature of authority. En A. Bieler, R. Higgott y G. Underhill (eds.), Non-state actors and authority in the global system (pp. 15-31). Londres: Routledge.

Foro Social Mundial (2001a). Carta de Principios del FSM Social Mundial. Recuperado http://www.alainet.org/es/active/1239

Foro Social Mundial (2001b). Declaración de los movimientos sociales.

Foro Social Mundial (2004). Declaración de los movimientos sociales.

Foro Social Mundial (2005). Raio X da Participação no Fórum 2005: elementos para o debate. São Paulo: IBASE.

Foro Social Mundial (2007). Llamado para un día de movilización y acción global. Recuperado de http://www.cadtm.org/Llamado-a-un-Dia-de-Movilizacion-y,2690

García Blanca, J. (2002). Porto Alegre 2002: ¿Transformaciones desde abajo o Reforma desde arriba? Recuperado de http://www.attacmadrid.org/d/2/o20223debate

Gill, S. (1993). Gramsci and global politics: Toward a post-hegemonic research agenda. En Gramsci, historical materialism and international relations (pp. 1-18). Cambridge: Cambridge University Press.

Gill, S. (2008). Power and resistence in the new world order. Nueva York: Palgrave McMillan.

Glasius, M. (2005). Deliberation or struggle? Civil society traditions behind the social forums. Ephemera, 5(2), 240-252.

Glasius, M. y Timms, J. (2005). Social Forums: Radical Beacon or Strategic Infrastructure? En M. Glasius, M. Kaldor y H. Anheier (eds.), Global Civil Society 2005-2006 (pp. 190-238). Londres: Sage. 
Hammond,J.L.(s/f).TheWorldSocialForumandtheRiseofGlobalPolitics.EnNACLA.Recuperado de https://nacla.org/article/world-social-forum-and-rise-global-politics

Kaldor, M. (2005). La sociedad civil global: una respuesta a la guerra. Barcelona: Tusquets.

Keck, M. y Sikkink, K. (2000). Activistas sin fronteras: redes de defensa en política internacional. México: Siglo XXI.

Khagram, S., Riker, J. V. y Sikkink, K. (2002). From Santiago to Seattle: Transnational advocacy groups restructuring world politics En S. Khagram, J. V. Riker y K. Sikkink (eds.), Restructuring world politics: Transnational social movements, networks, and norms (pp. 3-23). Minneapolis: University of Minnesota Press.

Klein, N. (2002). Vallas y ventanas. Barcelona: Paidós.

Laïdi, Z. (1997). Un mundo sin sentido. México: Fondo de Cultura Económica.

Massal, J. (2007). Sociedad civil internacional: ¿̇un poder global? Análisis Político, 2O(61), 54-72.

Muñoz Ramírez, G. (2003). EZLN: 20 y 10, el fuego y la palabra. México: La Jornada.

Paterson, B. (2009). Transformismo at the World Trade Organization. En M. McNally y J. Schwarzmante (eds.), Gramsci and global politics: Hegemony and resistence (pp. 42-57). Nueva York: Routledge.

Pleyers, G. (2010). Alter-globalization: Becoming actors in a global ag. Cambridge: Polity Press.

Said, E. (2002). Orientalismo. Madrid: Debate.

Sassen, S. (2007). Una sociología de la globalización. Madrid: Katz

Seoane, J. y Taddei, E. (2001). De Seattle a Porto Alegre: pasado, presente y futuro del movimiento antimundialización neoliberal. En J. Seoane y E. Taddei (comp.), Resistencias mundiales de Seattle a Porto Alegre (pp. 105-129). Buenos Aires: Consejo Latinoamericano de Ciencias Sociales.

Sklair, L. (2003). Sociología del sistema global. Barcelona: Gedisa.

Smith, J. (2004). Democratizing globalization? Impacts and limitations of transnational social movements. Ponencia presentada en American Sociological Association Annual Meeting, San Francisco, California.

Smith, J. et al. (2008). Global democracy and the world social forums. Londres: Paradigm Publishers. 
Steger, M., Goodman, J. y Wilson, E. K. (2013). Justice globalism: Ideology, crises, policy. Londres: Sage.

Tarrow, S. (1997). El poder en movimiento. Madrid: Alianza.

Tarrow, S. (2005). The dualities of transnational contention: "Two activist solitudes" or a new world altogether? Mobilization: An International Quarterly, 10(1), 53-72.

Tarrow, S. (2007). The new transnational activism. Nueva York: Cambridge University Press.

Teivainen, T. (2005). The World Social Forum: Arena or actor? En J. Leatherman y J. Webber (eds.), Charting transnational democracy (pp. 247-268). Nueva York: Palgrave Macmillan.

Teivainen, T. (2006). [WSF-Discuss] Interview with Teivo Teivainen on the WSF, social movements, and issues of power. Recuperado de http://openspaceforum.net/pipermail/worldsocialforum-discuss_openspaceforum.net/2006February/oooo55.html

Teivainen, T. (2012). Global democratization without hierarchy or leadership? The World Social Forum in the capitalist world. En S. Gill (ed.), Global crises and the crisis of global leadership (pp. 181-198). Londres: Cambridge University Press.

Tormey, S. (2004). Anti-capitalismo: A beginner's guide. Oxford: Oneworld.

Wallerstein, I. (2004). El Foro Social Mundial en la encrucijada. América Latina en Movimiento, 385-386.

Worth, O. (2013). Resistance in the age of austeriry. Londres: Zeld. 